\title{
Morphological Features of Pollen Grains in Portulaca
}

*Correspondence to:

Kim IS,

Tel: +82-53-580-5305

Fax: +82-53-580-5305

E-mail: botany@kmu.ac.kr

Received April 27, 2013

Revised May 21, 2013

Accepted June 7, 2013

\author{
InSun Kim* \\ Department of Biology, College of Natural Sciences, Keimyung University, Daegu 704-701, Korea
}

\begin{abstract}
The morphological features of pollen grains collected from the broad-leaved and cylindrical-leaved Portulaca species of the Hawaiian Islands were investigated. The variation in size and surface pattern were examined using scanning electron microscopy and statistical analysis. Pollens of the Portulaca were apolar grains of monads exhibiting apertures, colpi, and relatively thin echini. Of particular interest was the differing size of pollen grains among the species studied. Pollens of the broad-leaved Portulaca were considerable in size with a length of about $73 \sim 86 \mu \mathrm{m}$, while the cylindrical-leaved Portulaca tended to have smaller pollen grains ranging from 50 65 in diameter. The smallest pollens were found in cultivar 2 having an average of $43 \mu \mathrm{m}$. The pollen was intectate, and the exine surface appeared granulous, having sculptured elements of spinules and puncta. Two types of puncta were discerned; one forming an operculum, and the other, a simple perforation. Numerous spinules and small puncta were found throughout the cylindrical-leaved Portulaca. In the present study, morphological features of pollen grains from ten Hawaiian Portulaca species, including endemic and unknown taxa, revealed the aforementioned pattern of variation. This paper aim to provide morphological information that could be of phylogenetic value within the Hawaiian Portulaca.
\end{abstract}

Key Words: Morphology, Pollen, Portulaca, Surface ornamentation

\section{INTRODUCTION}

Flowers of Hawaiian Portulaca are perfect. They are slightly proterandrous and autogamous, as numerous viable seeds are produced from bagged flowers that possess normally developed anthers. Stamens vary in number greatly among species, ranging from $6 \sim 15$ in P. oleracea up to 94 in one of the cultivars, as examined in the study. Close correlation with the environmental influences or breeding system (Carolin, 1987; Kim \& Carr, 1990b) have been suggested as an explanation for such wide variation in stamen numbers. In general, about 80 120 mature pollen grains are produced per anther and pollen stain ability tests suggest relatively high pollen viability, except in cultivars (Kim \& Carr, 1990a, 1990b).

Small to relatively large circular pollen grains have been reported for this genus. The sizes of pollen grains determined for several Portulaca species ranged from about $40 \mu \mathrm{m}$ in P. villosa (Bennett, 1985) to $70 \sim 105 \mu \mathrm{m}$ in P. quadrifida
(Yun, 1989). Interestingly, two size classes of pollen grains corresponding to different cytotypes were found in P. grandiflora (Chopra, 1970). Furthermore, significant differences in the percentages of large and small grains between the two cytotypes, with the large-sized grains comprising more of the total sample within one cytotype than the other, were also noted in this species.

Other studies of pollen grains revealed pericolpate grains and slightly irregular exines (Bir \& Sidhu, 1980). Relatively large grains with a distinctive pericolpate arrangement of furrows were found in both fossil and modern pollen grains of P. oleracea (Byrne \& McAndrews, 1975). An unspecified Hawaiian taxon was described as having intectate grains with fairly uniformly spaced echini (Bennett, 1985; Yun, 1989).

In the genus Portulaca, the cosmopolitan P. oleracea and widely distributed $P$. pilosa have drawn attention, as they are speculated to be the plausible ancestral lineage for the ornamental Portulaca cultivars (Kim \& Carr, 1990a,

(a) This is an open-access article distributed under the terms of the Creative Commons Attribution Non-Commercial License (http://creativecommons.org/licenses/by-nc/3.0) which permits unrestricted noncommercial use, distribution, and reproduction in any medium, provided the original work is properly cited.

Copyrights @ 2013 by Korean Society of Microscopy 
1990b). In studies of reproductive biology, cytogenetics, and hybridization, using characteristics of vegetative and reproductive structures, a couple of unknown species and cultivars were described and their phylogeny has been roughly speculated (Kim \& Carr, 1990a, 1990b). Recently, the seed characteristics of several Portulaca species have shown to be useful in surveying their affinities with leaf morphology (Kim, 2012). Broad-leaved P. molokiniensis, and cylindrical-leaved P. sclerocarpa, and P. villosa are considered endemic Hawaiian species.

In the present study, morphological features of pollen grains from ten Hawaiian Portulaca species, including two unknown taxa, were examined to compare patterns of variation among them. This paper aims at providing morphological information that could be of phylogenetic value within Hawaiian Portulaca.

\section{MATERIALS AND METHODS}

Approximately 15 20 dehisced anthers and/or pistils with pollen grains on the stigma (Fig. 1A) were collected from numerous plants of three broad-leaved species ( $P$. oleracea, $P$. lutea, P. molokiniensis), five cylindrical-leaved species ( $P$. pilosa, $P$. villosa, $P$. sclerocarpa, $P$. sp. nov. $1, P$. sp. nov. 2) and two cultivars (broad-leaved cultivar 1, cylindrical-leaved cultivar 2 ). Fresh pollen samples collected from those species were used for both quantitative and qualitative data during the study. Sample size for the statistical analysis ranged from 50 to over 250 depending on the amount, condition, and availability of materials. An effort was made to take measurements from mature structures, and use of abnormally developed or immature materials was avoided. Zeiss Photomicroscope II (Zeiss, Oberkochen, Germany) was used to determine the sizes of pollen grains placed on the slides without mounting medium.

Anthers and pistils were processed as follows for the scanning electron microscopy. They were fixed for 2 4 hours in 3\% glutaraldehyde at room temperature and washed three times in $0.1 \mathrm{M}$ sodium phosphate buffer $(\mathrm{pH}$ 7.2). Fixed samples were dehydrated in a graded series of acetone followed by the critical point drying with liquid carbon dioxide (Emitech K850; Emitech Ltd., Ashford, UK). The processed samples were mounted directly on stubs using double sided adhesive tape and coated with gold/palladium in a sputter coater (Emitech K550X; Emitech Ltd.). The Samples were examined with Hitachi S-4200 SEM (Hitachi, Hitachi-Naka, Japan) at Daegu Center, Korea Basic Science Institute.

Diameters of pollen grains were determined by measuring grains as illustrated in Fig. 1. Statistical analyses of a multiple range test (Waller/Duncan test, ANOVA) using Statistical Analysis System (SAS Institute Inc., Cary, NC, USA) program were performed for comparisons among the species.
Significant differences were reported when the probability was less than $0.05(\mathrm{p}<0.05)$. The Waller/Duncan test was used to establish groups among ten species. All values stated to describe a given attribute throughout the paper represented mean values obtained during the basic statistical analysis.

\section{RESULTS AND DISCUSSION}

The current descriptions of pollen grains follow in general the terminology of Faegri and Iversen (1989) and of Moore et al. (1991). In flowering plants remarkable diversity has been shown, especially in the exines of pollen grains in their apertures and surface sculpturing (Twell et al., 2006), often elaborate in its patterning. In certain species, operculum of thick exinous lid covering the aperture can be forming either circular, elliptic, annular or bridge-like shapes (Thanikaimoni, 1986). The present study mainly focused on morphological features of the exines in their apertures and surface sculpturing.

Pollen grains of the Hawaiian Portulaca were free from each other as monads which were circular in outline. In almost all pollen grains, the polar axis and equatorial plane were not distinguished, indicating apolarity of the grains. Two different types of pollen grains, based on features of surface apertures, were observed in all taxa. Within the same anther, some grains did not show any clearly observable furrows, colpi, while most exhibited many conspicuous colpi in a pentagonal surface pattern (Fig. 1B). Those with apparent polygonal colpi were obviously pericolpate or pantocolpate with colpi evenly distributed over the entire surface of the grain (Fig. 1C). No meridional colpi were observed in the present study. They also had echini that were $1 \sim 3 \mu \mathrm{m}$ long. Further, distinct surface ornamentation was observed in the exine layer. The surface of the exine appeared granulous and the grain was intectate, having sculptured element such as spinules and puncta. The spinules were pointed projections not exceeding $3 \mu \mathrm{m}$ in length and the puncta were perforations with a diameter usually about $1 \mu \mathrm{m}$. The spinules ranged about $1 \sim 2$ $\mu \mathrm{m}$ in length and distributed in a fairly uniform fashion on the surface (Fig. 1D-H). Puncta showed very distinct features where each punctum was surrounded by a ring-shaped projection and raised orifice, operculum. A short tublar base was well defined in most cases. However, in P. villosa (Fig. 2A and B), P. sclerocarpa (Fig. 2C and D), and P. sp. nov. 2 the puncta appeared as simple perforations without distinct projections and operculum. Furthermore the diameter of puncta in these three taxa was much smaller than in all the other taxa studied in the genus (Fig. 2B and D). The diameters of puncta in the other species were usually less than $1 \mu \mathrm{m}$. Occasionally, puncta of $1 \sim 1.5 \mu \mathrm{m}$ in diameter were observed along with many small puncta on the same pollen surface in $P$. lutea, P. molokiniensis, and cultivar 1. More numerous spinules 
and small puncta were generally found in cylindrical-leaved species than in broad-leaved species and the two cultivars (Fig. $2 \mathrm{E}-\mathrm{H})$. Frequently, the surface covered with sporopollenin, secreted through microchannels of the exine layer (Rowley, 1990), was well-observed in the operculum (Fig. 2H).

Although similar in morphology, the pollen grains of Portulaca exhibited variation in size. Large grains were found in the broad-leaved $P$. oleracea and $P$. lutea, the pollen grains averaged about 73 74 $\mu \mathrm{m}$. The largest grains, $86.0 \mu \mathrm{m}$, were found in P. molokiniensis. cultivar 1 also had large grains, $75 \mu \mathrm{m}$, as in $P$. oleracea and $P$. lutea. The smaller grains, ranging from 50 to 65 $\mu \mathrm{m}$, were observed in cylindrical-leaved species (Table 1). The smallest grains, $43 \mu \mathrm{m}$, were found in cultivar 2. However, an interspecific size variation was noticed in a plant and even in a
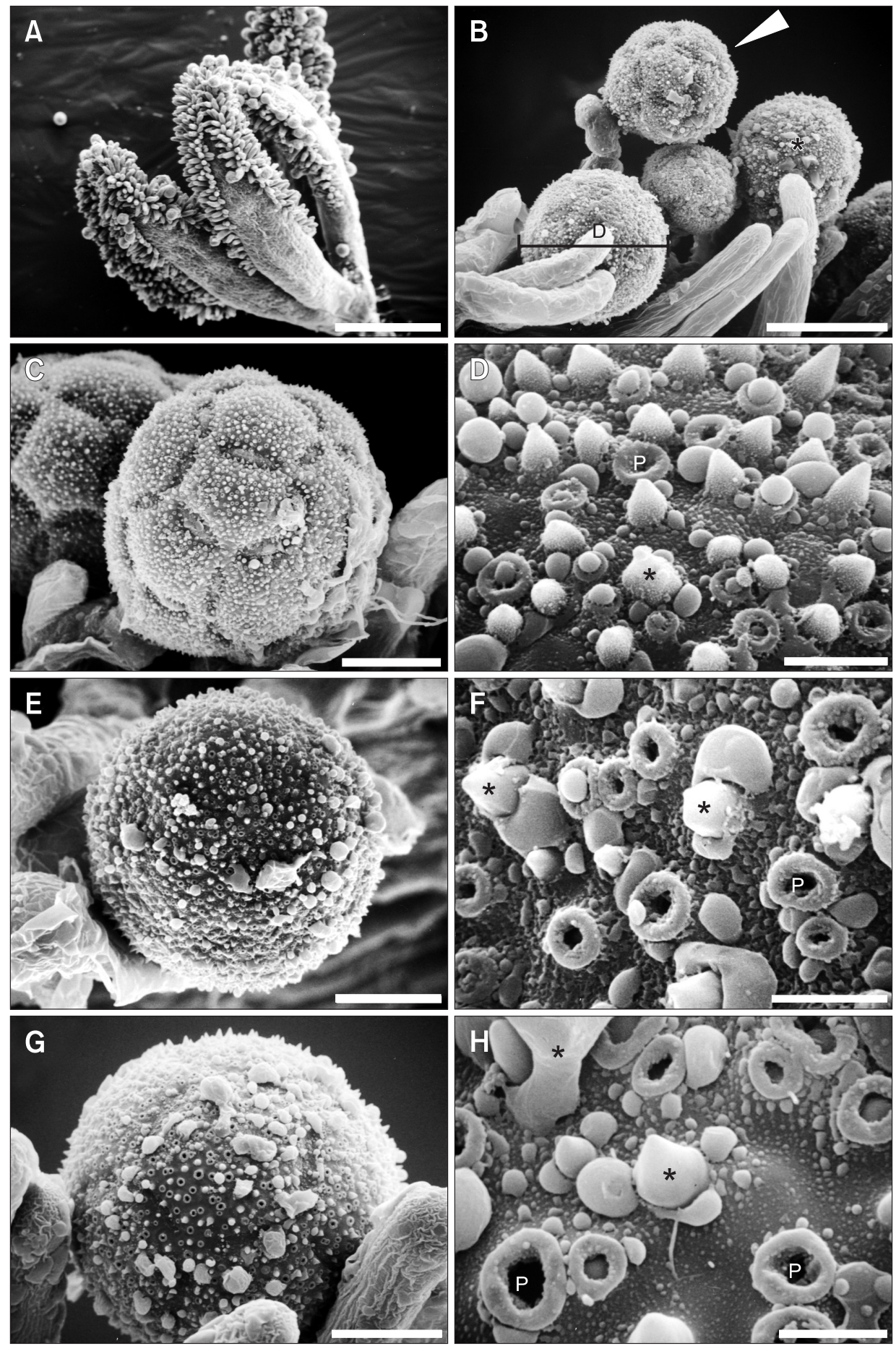

Fig. 1. (A) Side view of the stigma from Portulaca pilosa. Bar $=400 \mu \mathrm{m}$. (B) Pollen grains on the stigmatic surface with colpi (arrowhead) and without colpi (asterisks). $\mathrm{D}$, diameter. $\mathrm{Bar}=30 \mu \mathrm{m}$. Pollen grains of broad-leaved $P$. oleracea (C, D), $P$. lutea $(\mathrm{E}, \mathrm{F})$ and $P$. molokiniensis $(\mathrm{G}, \mathrm{H})$. ' $\mathrm{P}$ ' denotes puncta. Asterisks indicate the sporopollenin secreted around the operculum. Bar represents $20 \mu \mathrm{m}$ in Fig. 1C, E, G and $2 \mu \mathrm{m}$ in Fig. 1D, F, and H. 
single flower.

Both pollen grains of pericolpate pattern or circular grains without clear colpi seemed viable on the basis of stain ability tests and SEM observations. The presence of such types of grains within anther might be due to varying moisture content in different pollen grains at the time of sampling. It has been reported that the colpi appeared as narrow slits when the exine was contracted in dry, living grain, whereas the thin membrane of the colpi expanded and bulged out when the grain was moistened (Faegri \& Iversen, 1989; Malho, 2006). This observation prompts consideration of the idea that the grains without clearly visible colpi may be the moistened ones and might have shown the same morphology as pericolpate when they were moistened.
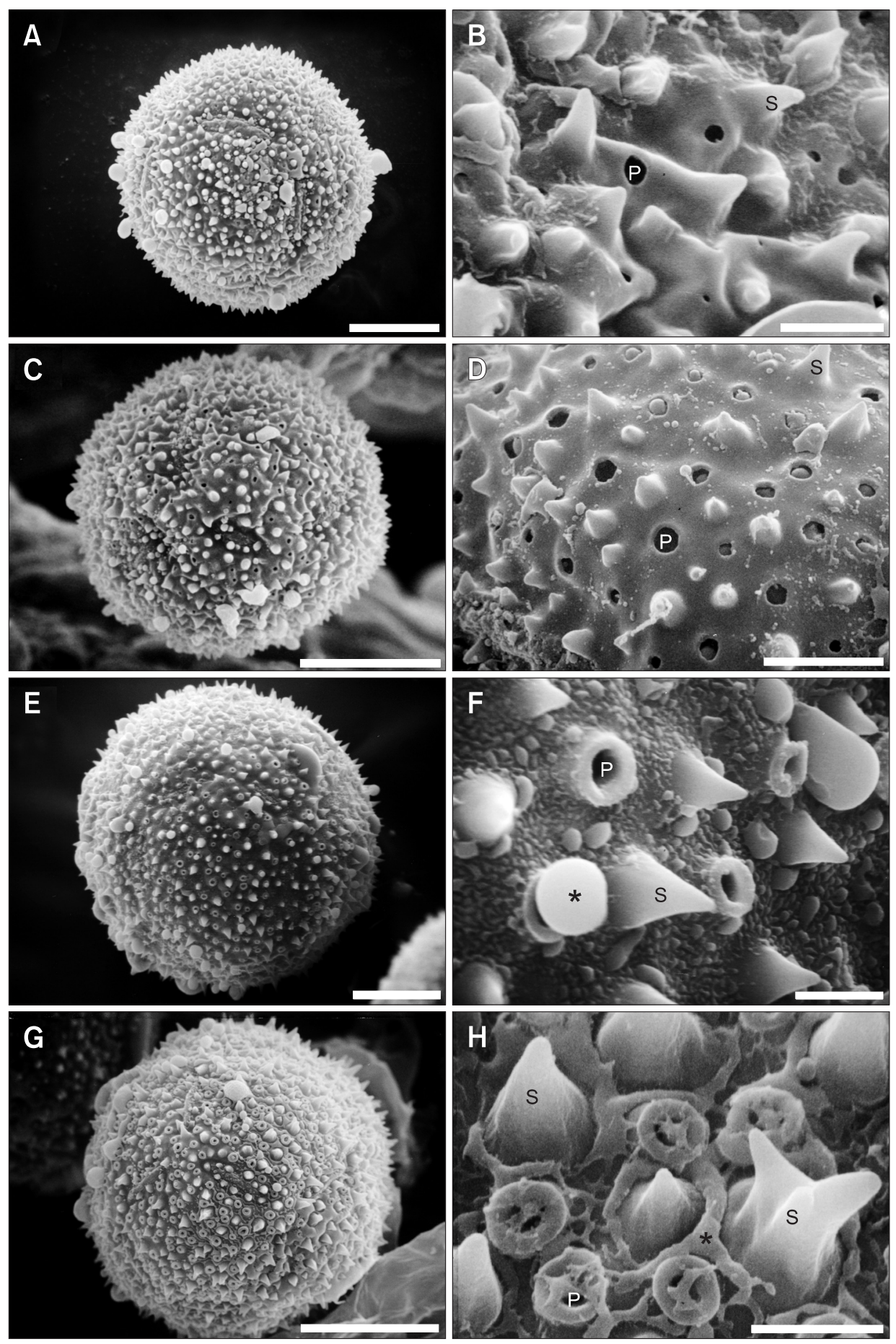

Fig. 2. Pollen morphology of cylindricalleaved Portulaca and cultivars. (A, B) $P$. villosa, (C, D) P. sclerocarpa, (E, F) cultivar 1 , and $(\mathrm{G}, \mathrm{H})$ cultivar 2. ' $\mathrm{P}$ ' denotes puncta and ' $\mathrm{S}$ ' denotes sporopollenin. Arrowheads indicate the operculum. Bar represents $15 \mu \mathrm{m}$ in Fig. $2 \mathrm{~A}, 20 \mu \mathrm{m}$ in Fig. C, E, G and $2 \mu \mathrm{m}$ in Fig. 2B, D, F, and $\mathrm{H}$. 
Table 1. Comparison of pollen grains size (diameter: $\mu \mathrm{m}$ ) in Portulaca examined

\begin{tabular}{|c|c|c|c|c|c|c|c|}
\hline Taxon & $\mathrm{n}$ & $\mathrm{x}$ & SD & SE & Range & \multicolumn{2}{|c|}{ Waller/Duncan } \\
\hline P. oleracea & 100 & 73.2 & 10.3 & 1.0 & $47.9 \sim 95.7$ & B & B \\
\hline P. lutea & 255 & 73.9 & 11.5 & 0.7 & $55.1 \sim 101.5$ & B & B \\
\hline P. molokiniensis & 50 & 85.6 & 5.6 & 0.8 & $66.7 \sim 107.3$ & A & A \\
\hline \multicolumn{8}{|c|}{ Cylindrical-leaved group } \\
\hline P. pilosa & 51 & 60.8 & 9.4 & 1.3 & $36.3 \sim 82.7$ & $\mathrm{D}$ & $\mathrm{DE}$ \\
\hline P. villosa & 102 & 57.3 & 8.4 & 0.8 & $39.2 \sim 85.6$ & $\mathrm{E}$ & $\mathrm{EF}$ \\
\hline P. sclerocarpa & 100 & 49.7 & 10.6 & 1.1 & $24.7 \sim 79.8$ & $\mathrm{~F}$ & G \\
\hline$P$. sp. nov. 1 & 157 & 54.9 & 9.5 & 0.8 & $36.3 \sim 88.5$ & $\mathrm{E}$ & $\mathrm{F}$ \\
\hline P. sp. nov. 2 & 50 & 65.2 & 2.9 & 0.4 & $58.0 \sim 71.1$ & $\mathrm{C}$ & $\mathrm{C}$ \\
\hline \multicolumn{8}{|c|}{ Broad-leaved cultivar } \\
\hline Cultivar 1 & 116 & 74.8 & 21.4 & 2.0 & $46.0 \sim 108.8$ & B & B \\
\hline \multicolumn{8}{|c|}{ Cylindrical-leaved cultivar } \\
\hline Cultivar 2 & 50 & 42.8 & 6.6 & 1.0 & $30.5 \sim 56.6$ & G & $\mathrm{H}$ \\
\hline
\end{tabular}

SD, standard deviation; SE, standard error.

Of particular interest was the size of pollen grains among the species in comparison. Relatively large pollen grains were found among broad-leaved species, while other species tended to have smaller pollen grains. Another interesting feature noticed during the study was the presence of many different sized pollen grains within the same anther. In a given species, the largest grains were typically twice as big as the small grains. The widest variation was detected in P. sclerocarpa where some grains were vastly larger than others. The smallest variation in size was shown in $P$. sp. nov. 2 . This was not unexpected since only one genotype was available for this species where adequate care was taken for handling the singlepollen genotyping to avoid any contamination (Suyama, 2011).

Size classes of pollens corresponded to different cytotypes as in other Portulaca were not attempted here, since several chromosome numbers with polyploidy has been speculated in the Hawaiian Portulaca (Kim \& Carr, 1990b). Some of the previous palynological estimates (Nyananyo, 1992) were not congruent with those of the present materials, but the difference might result from the different treatment of mounting media used for the examination. Grain size, when measured, is believed to be affected by preparation procedures and the requirement of measurement under identical conditions has been stressed. All mounts utilized for size measurements in this study were subjected to relatively uniform conditions of preparation, but a considerable range in size was still observable within a single preparation. When the pollen grains were examined, either with or without any mounting media, the size variation was still observable. Pollen grains mounted in aniline blue appeared to be about 10 20\% larger than fresh dry pollen. Data of the pollen volume were not estimated since pollen grains processed for the SEM have shown changes in their volume. Thus, the use of pollen grain size as a sole factor in the delineation of taxa has been avoided in this study. Many factors including occurrence of inherent variation have contributed to pollen size variability (Punt, 1986; Nepi \& Franchi, 2000; Nepi et al., 2001). Further phylogenetic and molecular work on reproduction and/ or experimental hybridization has provided new data on resolving the status of unknown and/or endemic species with a close affinity (Baldwin \& Wagner, 2010; Kim, 2012).

\section{CONCLUSIONS}

Pollens of the Hawaiian Portulaca are monads exhibiting apolarity grains. Of particular interest in the present study was the size of pollen grains among the species in comparison. Although similar in morphology, the pollen grains of Portulaca exhibited variation in size. The largest grains, $86.0 \mu \mathrm{m}$, were found in P. molokiniensis., and the smallest, $43 \mu \mathrm{m}$, in cultivar 2. Pollens were mostly large in the broad-leaved Portulaca, with a size of about $74 \sim 86 \mu \mathrm{m}$, while cylindrical-leaved Portulaca tended to have smaller pollen grains ranging from $50 \sim 65 \mu \mathrm{m}$, except in cultivars.

Based on features of surface apertures, polygonal colpi were obviously pericolpate or pantocolpate, and they were evenly distributed over the entire exine surface with distinct ornamentation. The pollen was intectate and the exine surface appeared granulous, having the sculptured element of spinules and puncta. Approximately $1 \sim 2 \mu \mathrm{m}$ spinules were found to be distributed in a fairly uniform fashion on the surface. Puncta showed distinct features in many of the species by forming an operculum as a ring-shaped and 
raised orifice, although others exhibited simple perforations. Numerous spinules and small puncta were found throughout the cylindrical-leaved Portulaca species.

\section{REFERENCES}

Baldwin B G and Wagner W L (2010) Hawaiian angiosperm radiations of North American origin. Ann. Bot. 105, 849-879.

Benett T M (1985) Palynology of selected horizons from the Ewa coastal plain, Oahu, Hawaii. Master's thesis. University of Hawaii at Manoa, Honolulu.

Bir S S and Sidhu M (1980) Cyto-palynological studies on weed flora of cultivable lands of Patiala District (Punjab). J. Palynol. 16, 85-105.

Byrne R and McAndrews J H (1975) Pre-Columbian purslane (P. oleracea L.) in the New World. Nature 25, 726-727.

Carolin R (1987) A review of the family Portulacaceae. Aust. J. Bot. 35 , 383-412.

Chopra S K (1970) Cytopalynological studies in Portulaca grandiflora. Palynol. Bull. 6, 8-9.

Faegri K and Iversen J (1989) Textbook of Pollen Analysis. pp. 62-162, (The Blackburn Press, Caldwell).

Kim I (2012) Anatomical and morphological features of seeds in Portulaca. Appl. Microsc. 42, 194-199.

Kim I and Carr G D (1990a) Cytogenetics and hybridization of Portulaca in Hawaii. Syst. Bot. 15, 370-377.

Kim I and Carr G D (1990b) Reproductive biology and uniform culture of Portulaca in Hawaii. Pac. Sci. 44, 123-129.

Malho R (2006) The Pollen Tube: A model system for cell and molecular biology studies. In: The Pollen Tube: A Cellular and Molecular Perspective. Plant Cell Monogr (3), ed. Malho R, pp. 1-13, (SpringerVerlag, Berlin).

Moore P D, Webb J A, and Collinson M E (1991) Pollen Analysis. pp. 62
162, (Blackwell Scientific Publications, Oxford).

Nepi M and Franchi G G (2000) Cytochemistry of mature angiosperm pollen. In: Pollen and Pollination, eds. Dafni A, Hesse M, Pacini E, pp. 45-62, (Springer-Verlag, Wien).

Nepi M, Franchi G G, and Pacini E (2001) Pollen hydration status at dispersal: cytophysiological features and strategies. Protoplasma 216, 171-180.

Nyananyo B L (1992) Pollen morphology in Portulacaceae (Centrospermae). Folia Geobot. Phytotax. 27, 387-400.

Punt W (1986) Functional factors influencing pollen form. In: Pollen and Spores: Form and Function, ed. Blackmore S and Ferguson I K, pp. 97-108, (Academic Press, London).

Rowley J R (1990) The fundamental structure of the pollen exine. PI. Syst. Evol. (Suppl.) 5, 13-29.

Suyama Y (2011) Procedure for single-pollen genotyping. In: Single-Pollen Genotyping, ed. Isagi Y and Suyama Y, pp. 7-15, (Springer, Tokyo).

Thanikaimoni G (1986) Pollen apertures: form and function. In: Pollen and Spores: Form and Function, ed. Blackmore S and Ferguson I K, pp. 119-136, (Academic Press, London).

Twell D, Oh S, Honys D (2006) Pollen Development, a genetic and transcriptomic view. In: The Pollen Tube: A Cellular and Molecular Perspective. Plant Cell Monogr (3), ed. Malho R, pp. 15-45, (SpringerVerlag, Berlin).

Yun I K (1989) Biosystematics and ultrastructure of Portulaca in Hawaii. Ph. D. Dissertation. University of Hawaii at Manoa, Honolulu. 